\title{
AKED远A \\ ADMINISTRAÇÃO DO ESTOQUE DE EMPRESAS COM USO DE ESTATÍSTICA
}

\author{
English title: STOCK ADMINISTRATION OF COMPANIES USING STATISTICS
}

\section{doi>10.33726/akdpapers2447-7656v11a72021p36-57}

SILVA, Marcelo Júnio da ${ }^{1}-$ marcelo.1015700@discente.uemg.br
CARMO, Wesley Pereira do ${ }^{2}-$ wesley.1015580@discente.uemg.br
FREITAS SILVA, Josney ${ }^{3}$ - (iD https://orcid.org/ 0000-0002-9349-4497

RESUMO: O objetivo deste estudo é o de demonstrar o modo com que os aparatos estatísticos são utilizados em departamentos específicos das empresas, os quais são tidos como parte básica de seus planejamentos estratégicos, condição que tem requisitado dos gestores um fluxo de tomada de decisões mais poderosas. A metodologia de pesquisa empregada foi a do método indutivo associado à revisão bibliográfica. Como resultados parciais do estudo, ressalta-se que o uso de estatísticas como apoio de análise, geralmente visa a atingir a escolha mais sensata dentre o rol de ferramentas usadas para controlar estoques. Justifica a realização da pesquisa, o atual estágio, em que mais se tem discutido a relevância do uso de cálculos e dados, vistos como aliados às teorias do campo da estatística, as quais amparam a pesquisa operacional para a tomada de decisões bem-sucedidas pelos gerentes.

PALAVRAS-CHAVE: Previsão de Demanda, Análise de Regressão, Software $R$

ABSTRACT: The objective of the study is to demonstrate the way in which statistical devices are used in specific departments of companies, which are seen as a basic part of their strategic planning, a condition that has required managers to have a more powerful decision-making flow. The research methodology employed was that of the inductive method associated with the literature review. As partial results of the study, it is emphasized that the use of statistics as support for analysis, generally aims to achieve the most sensible choice among the list of tools used to control stocks. It justifies the conduct of the research, the current stage in which the relevance of the use of calculations and data has been discussed the most, seen as allies with theories in the field of statistics, which support operational research for successful decision making by managers.

KEYWORDS: Demand Forecasting, Regression Analysis, Software R

\footnotetext{
${ }^{1}$ Graduando em Administração. Universidade do Estado de Minas Gerais - Unidade Frutal/MG.

${ }^{2}$ Graduando em Administração. Universidade do Estado de Minas Gerais - Unidade Frutal/MG.

${ }^{3}$ Doutor em Ensino de Ciências e Matemática. Mestre em Ensino de Ciências. Especialista em Gestão de Pequenas e Médias Empresas. Especialista em Gestão Empresarial Estratégica. Licenciado em Matemática e Pedagogia. Professor efetivo na Universidade do Estado de Minas Gerais - UEMG Unidade Frutal/MG. E-mail:<josney.silva@uemg.br>.
} 


\section{AKED恶}

\section{INTRODUÇÃO}

Observa-se que, graças aos números, é possível que se obtenha informações que minimizem o risco na gestão das empresas, razão pela qual a Estatística é ainda mais utilizada como importante ferramenta na estruturação e no planejamento de diversos setores empresariais, principalmente na tomada de decisões. E, vais mais além, visto que, aquele que detém mais conhecimento em determinada área, se destaca, alcança melhores espaços no mercado profissional e se valoriza como ser humano.

A Estatística é uma Ciência precisa, usada para coletar, organizar, analisar e registrar dados por amostragem. Desde a Antiguidade, isso tem sido feito para registrar dados sobre a vida e a morte das pessoas, sendo, portanto, um método de investigação básico para a tomada de decisões, tendo em vista que suas conclusões são baseadas em armazenagem e análise de dados (LEVIN; FOX, 2004).

Segundo apresentam Krajewski, Malhotra e Ritzman (2017), o equilíbrio entre a oferta e demanda tem origem em previsões precisas que podem ser conciliadas por toda a cadeia de suprimentos. Uma previsão pode ser considerada como um prognóstico de eventos, costumeiramente utilizada com a finalidade de auxiliar no planejamento. Por sua vez, esse planejamento consiste no processo de tomada de decisões gerenciais a partir das quais se determina como mobilizar recursos para atender às previsões de demanda da melhor forma possível.

Neste contexto, os métodos de previsão geralmente são baseados em modelos matemáticos, utilizando dados históricos e ou métodos qualitativos, que se baseiam na experiência administrativa e nas avaliações dos gerentes.

Nesta pesquisa, vale dizer, que o foco recai sobre as previsões de demanda, mais especificamente em métodos causais, com auxílio do Software $R$, que é uma ferramenta computacional, disponibilizada sob os termos ditados pela General Public License da Free Software Foundation (GNU), na forma de código aberto. 


\section{AKEDIA}

Ao contrário das grandes empresas, que possuem sistemas computacionais integrados que possibilitam obter informações confiáveis para a administração dos estoques, as pequenas empresas não possuem recursos financeiros suficientes para adquirir estes sistemas e, consequentemente, a tomada de decisões se dará de forma empírica, sem a acertividade possibilitada pelo uso de métodos estatísticos complexos.

Neste sentido, define-se como objetivo desta pesquisa, identificar uma alternativa viável e compatível para as pequenas empresas possam realizar a previsão de demanda, que se faz necessária para tomada de decisão em administração de estoques, utilizando ferramentas estatísticas e recursos computacionais eficientes.

Como parte do lastro teórico deste estudo, vemos que Moretti (2010) apresenta a Estatística como uma Ciência fornecedora de princípios e de metodologias úteis para coletar, organizar, apresentar, resumir, analisar e interpretar dados. Logo, seguindo esse raciocínio, repete-se que esse entendimento transforma-se em substrato essencial de diversos setores, principalmente no campo da pesquisa.

Assim, é graças a estudos estatísticos, que se torna possível aumentar os lucros corporativos, melhorar as propriedades dos produtos ou processos, diminuir custos, decidir sobre o valor econômico ou político e o aumento da análise crítica, o que, em última análise, contribui para justificar esta pesquisa.

No roteiro de nossa análise, vemos que, ao examinar a empresa, delimitam-se claramente, ao menos, quatro grandes áreas: Finanças, Marketing, Recursos Humanos e Produção. Daí é provável identificar que os procedimentos estatísticos têm um impacto direto ou indireto em cada um destes segmentos. À medida que em Finanças e Produção existem análises que mostram recursos quantitativos e os resultados os afetam diretamente, nos campos de Recursos Humanos e do Marketing o impacto é indireto.

Consoante Andrade et al. (1996), considera-se que as estatísticas utilizadas são baseadas em observação experimental e a teoria tornou-se item importante do método científico. Pode-se dizer que a Ciência contemporânea sofre uma "invasão", por meio de métodos matemáticos em campos diversos 


\section{AKEDIAA}

como Economia, Engenharia, Sociologia, Biologia, Medicina, Psicologia etc. Portanto, é fundamental para profissionais e técnicos de diversas áreas de formação básica sólida em ciências, conhecer os conceitos e métodos mais comumente usados em análises estatísticas.

Quanto a natureza, esta pesquisa classifica-se como aplicada, pois procura produzir conhecimentos para aplicação prática direcionado à solução de problemas específicos. Quanto ao método científico, classifica-se como método indutivo, ao entender que o argumento passa do específico para o geral, em que as generalizações têm origem em casos da realidade concreta. Quanto a abordagem, classifica-se como quantitativa, uma vez que requer o uso de recursos e técnicas de Estatística, com o intuito de traduzir em números os conhecimentos gerados pelo pesquisador (PRODANOV; FREITAS, 2013).

\section{CONCEITOS BÁSICOS DA ESTATÍSTICA}

Segundo Silva et al (2010), o termo Estatística foi utilizado inicialmente para denominar levantamentos de dados, que tinham como finalidade orientar o Estado em suas decisões.

Desde então, foi utilizado ao longo do tempo para determinar o valor dos impostos cobrados dos cidadãos, para auxiliar na estratégia de uma nova batalha em guerras e teve um acelerado desenvolvimento a partir do século XVII, por meio de estudos de Bernoulli, Fermat, Pascal, Laplace, Gauss, Galton, Pearson, Fisher, Poisson e outros que ajudaram na constituição das suas características atuais.

De acordo com Bonafini (2012), a Estatística é o campo da Matemática que conecta fatos e números. Nessa ponte teórica, há um conjunto de métodos que nos permite coletar e analisar dados para que possamos explicá-los.

A Estatística, per se, é dividida em duas partes: a) descritivas e b) inferenciais. A marca característica da Estatística descritiva é a organização, análise e apresentação dos dados, enquanto a característica marcante da Estatística inferencial é o estudo de amostras de uma população específica, a análise e a apresentação dos dados nesta base. 


\section{AKEDIA}

Para McClave, Benson e Sincich (2009), a Estatística é uma Ciência importante, de utilidade quase ilimitada e com escopo abrangente de aplicações em negócios, administração política, na Física e nas Ciências Sociais.

Estatísticos são treinados em Ciência Estatística, ou seja, eles são treinados para coletar informações numéricas na forma de dados, que são analisados e, por intermédio deles, abstrair conclusões. Além disso, a Estatística pode auxiliar na determinação de qual informação é relevante em um determinado problema e determinar se as conclusões extraídas podem ser confiáveis. Para interpretar o resultado após a aplicação do método estatístico, é necessário conhecer algumas concepções utilizadas nesse campo de estudos, que são primordiais para a compreensão dos resultados.

Desse modo, vale lembrar que a análise cobre os seguintes princípios, segundo Webster (2006): a população é um agrupamento de todos os elementos e itens; os parâmetros são particularidades que representam a população; a amostra é parte dessa população que será averiguada; a variável é uma característica específica da população que será verificada; os dados são valores adquiridos no estudo; estimador é o atributo numérico encontrado na amostra; e, observação é a descrição do que se aprecia. A par do desenvolvimento destas práticas próprias da Estatística, foi possível obter dados e analisá-los de forma mais eficaz, permitindo o controle e investigação adequada de fenômenos, fatos, acontecimentos nas várias áreas do conhecimento. Assim, as estatísticas objetivas fornecem métodos e técnicas para lidar racionalmente com situações de incerteza.

Deve-se recordar que em geral, na economia ou nas grandes empresas, há setores que geram muitos dados e, em tais casos, a amostragem é a melhor modalidade a ser aplicada como método de pesquisa. O implica dizer, consequentemente, que testar toda a população se torna muito caro e trabalhoso, permitindo que uma pesquisa preliminar seja realizada para encontrar parâmetros e, em seguida, buscar uma amostra que tenha um resultado confiável, sendo menos trabalhosa e menos onerosa (WEBSTER, 2006). 


\section{AKED』A}

\section{A RELEVÂNCIA DA ESTATÍSTICA NAS QUATRO ÁREAS DA EMPRESA}

Em nossa sociedade moderna, novos requisitos para a leitura de códigos e linguagens foram introduzidos na mídia e no dia a dia da organização. Segundo Rossetti Júnior (2007), quase todas as mídias, como jornais, revistas, rádio, televisão e internet, utilizam modelos estatísticos como gráficos, quadros, pictogramas, tabelas e pesquisas para integrar e enriquecer seus conjuntos de informações a serem divulgadas ao público. E, em todos os casos, ainda pode existir um sistema de negócios que lançará mão de estatísticas para gerenciar suas atividades comerciais.

Por isso, o emprego da Estatística deve ser estudado por todos os especialistas que desejem a inserção no mercado de trabalho para agregar às suas características profissionais a capacidade de lidar com sua realidade.

Desse modo, construindo um repertório estatístico, ele tentará basear suas práticas na seleção de indicadores mais ou menos selecionados em acordo com a conveniência do momento, alicerçando os objetivos de seus projetos de forma contextual.

E é assim que Rossetti Júnior (2007) ressalta que o mundo coorporativo passou a utilizar a linguagem estatística em suas rotinas operacionais, exigindo dos profissionais conhecimentos e competências numéricas para o correto entendimento e produção de relatórios, tabelas, gráficos, diagramas e fluxogramas.

A esfera financeira é de grande utilidade em estudos estatísticos, uma vez que se dedica a lucros, custos, despesas, avaliações, análises de processos, entre outros. Um gerente deve ter uma visão genérica da empresa para agir. Os números fornecem interpretações mais precisas e fornecem maior confiabilidade operacional.

O domínio dos ciclos de produção se preocupa com os métodos usados para verificar dados relacionados a produtos, processos ou funcionários. É nesta esfera que existe a imposição de monitoração, por exemplo, administração de qualidade do produto. São gráficos que expõem o andamento e as imperfeições de cada mercadoria em cada processo, permitindo que você 
pare a criação e faça manutenções, e ainda descubra novas formas de completar cada trabalho (MCCLAVE; BENSON; SINCICH, 2009).

De acordo com Faber e Larson (2009), na área de comercialização, notado pelos leigos como publicidade da empresa, mas é um campo fundamental que abrange todo o resto, da mesma forma pode-se recorrer à Estatística. A comercialização impulsiona o negócio, é a figura que as empresas pretendem transmitir aos seus clientes e, por isso, é fundamental.

Nesse ponto, cujo enfoque trata da comercialização, também é salutar indagar como as conclusões quantitativas podem ajudar o marketing? Como a publicidade é a exposição visual da comercialização na qual o cliente analisa o artefato e decide se gosta ou não, é primordial uma metodologia de verificação da corroboração do produto. As estatísticas podem investigar a população por amostragem para julgar a aceitação ou adesão média de um produto por anúncio e até mesmo averiguar a aprovação de amostra por anúncio.

Segundo Ulrich et al (2013), os recursos humanos são extremamente importantes para as empresas, sendo bem feita, porque se preocupa com as pessoas. O segmento dos Recursos Humanos é encarregado por mediar as associações entre o empregado e o empregador, buscando manter a regularidade na empresa e agregar potencial a ela para que cresça e se desenvolva, bem como seus colaboradores. Visto que os Recursos Humanos lida com assuntos humanos, os dados quantitativos raramente são usados nesta área. As tarefas utilizam avaliações qualitativas, testes e dinâmicas, omitindo valores quantitativos.

Entretanto, ao verificar os resultados dos colaboradores da empresa, é plausível verificar dilemas com os funcionários. Como exemplo, um colaborador que produz, em média, uma quantia de peças e, abruptamente, passa a produzir mais ou menos do que o normal.

Com esse resultado estatístico, se poderá intervir e verificar as razões pelas quais esse resultado poderá aperfeiçoar não só o bem-estar no trabalho, mas também de todos na empresa. 


\section{A UTILIZAÇÃO DAS FERRAMENTAS ESTATÍSTICAS NA EMPRESA}

Do ponto de vista do mercado, de acordo com a lógica da concorrência, as empresas devem projetar para aumentar a satisfação dos clientes e outros grupos de interesse mais eficaz do que os concorrentes (LEANDRO, 2008).

Marshall Júnior et al. (2006), declara que a gestão do processo era essencial desenvolvimento de técnicas estatísticas do controle de qualidade. Assim, ao criar-se uma estrutura, organizam-se as etapas envolvidas na conclusão do trabalho ou tarefa, incluindo o fluxo, os insumos, as atividades realizadas e os produtos produzidos, fornecendo informações estruturadas e o reconhecimento de pontos críticos, de oportunidades de melhoria e, principalmente, de desvios ou flutuações devido a causas normais (inerentes à natureza processo).

Corrêa e Corrêa (2006) enfatizam que ferramentas não resolvem problemas e nem mesmo tornam as coisas melhores, na verdade as ferramentas suportam e ajudam pessoas na apoderação de decisões que irão resolver problemas e melhorar a situação.

Alves (2003), precursor desse pensamento, informa que devem ser utilizadas técnicas para atingir o nível de qualidade em estatísticas convenientes, e que se baseiem no compromisso geral dos envolvidos, que é, em suma, o da melhoria total para a estabilidade do processo.

Para análise geral, quando a proporção de amostras for grande, elas serão analisadas. Porém, ainda é difícil estabelecer os dados a serem analisados. Em conformidade com McClave, Benson e Sincich (2009), um dos essenciais propósitos da estatística inferencial, é o de usar dados de demonstração para estimar o valor de um parâmetro desconhecido da população (estimativa de parâmetro).

Mesmo acompanhando essa linha de argumentação, uma apresentação é uma ferramenta básica e, se bem utilizada, permite que um administrador tome providências com segurança. As seleções só produzirão resultados efetivos se forem baseadas em dados de precisão ou de certa maneira comprovados pelo uso correto dessas amostragens. 


\section{AKED』A}

A "Média", que é mais um dado estatístico, garante à empresa uma situação real, o quão longe está do mercado. Por exemplo, observando-se a quantidade de peças vendidas a cada seis meses de uma peça de automóvel, há uma maneira de se ter mais controle sobre seu estoque. Assim, a mediana, a moda, a média ponderada e a média geométrica também são responsáveis pela análise das observações em busca de um número central estratégico.

"Variância" e "Desvio Padrão" têm como objetivo medir a distância de suas observações ou dados da "Média". Em função dessas pesquisas, a companhia pode determinar em que momento seus critérios saem do caminho, ou seja, quando o produto é fabricado além do que necessita.

Como exemplo de "Variação", temos que, uma falha de máquina pode ocorrer em uma série de criação de pneus, que forma a borracha de um pneu. Desta forma, ocorrerá uma alteração na forma do pneu, o que afetará o resultado esperado. Isso pode ser evitado com o uso do cartão de controle e até mesmo durante a manutenção do equipamento, ou seja, durante a inspeção, no acompanhamento da qualidade. Permanecendo no exemplo da variância, porém, por meio do resultado final, que só ficou perceptível após a análise daquela variância ocorrida no perímetro, por exemplo, a borracha, será considerada inofensiva para a companhia.

$\mathrm{Na}$ produção de estatísticas, espera-se a cooperação de sistemas implantados na empresa, incluindo na obtenção de materiais, controle de estoque, compras. Portanto, a administração deve buscar softwares que facilitem o emprego de equipamentos estatísticos e, assim, que se ampliem a qualificação dos indivíduos para aperfeiçoarem-se na área de análise de dados.

Em concordância com Neufeld (2003), na Administração, você pode utilizar métodos estatísticos para planejar e controlar a produção, buscando implementar técnicas administrativas eficazes que garantam maiores lucros e menores custos, estimando receitas, prevendo estoques e demanda e, principalmente, conhecendo o mercado e seus clientes.

A "Probabilidade", ao seu turno, associa um número às chances de um determinado resultado; portanto, quanto maior o número, maior a possibilidade 
de o resultado ocorrer. Esta ferramenta é uma parte da Estatística utilizada na maioria das empresas, posto que possibilite maior assertividade nas escolhas a serem tomadas pela empresa, quantificando a probabilidade de ocorrer um evento esperado. Como exemplo, cita-se que uma companhia de ensinamentos em informática desenvolverá uma proposta para lecionar para maiores de 60 anos. Visando se eles terão interesse, é necessário realizar uma consulta de campo para averiguar a rentabilidade do projeto.

\section{CONCEITO E CARACTERIZAÇÃO DOS ESTOQUES}

Slack, Chambers e Johnston (2002), definem estoques como o acúmulo de recursos materiais em um sistema de transformação. Segundo Corrêa e Corrêa (2005), quatro tipos de estoques podem ser definidos em função de sua localização no processo operacional: (i) estoques de matérias-primas e componentes adquiridos, (ii) materiais em andamento, (ii) estoques de produtos acabados e (iv) estoques de materiais para MRO (manutenção, reparo e operação), também conhecido como estoque de peças de reposição.

Diante da incerteza da demanda, o estoque tem papel fundamental para garantir a segurança da empresa. Manter o nível de estoque correto aumenta a probabilidade de que os consumidores possam usar o produto no momento da compra. Esta definição é chamada de nível de serviço prestado aos consumidores (WANKE, 2003).

Um dos principais desafios da administração moderna é o de se obter maiores nível de serviço aos clientes e diminuir os custos de manutenção dos estoques (GAVIOLLI; BARBIERI, 2007; BALLOU, 2006). Ballou (1993) já mencionara outros benefícios de manter o estoque: (i) estimular a produção, (ii) permitir economias de escala para compras e transporte, (ii) evitar alterações de preços de fornecedores, (iv) evitar flutuações de demanda ou preços e tempo de reabastecimento, e (v) Previna emergências.

Por outro lado, a manutenção de altos níveis de estoque esconde a ineficiência do processo produtivo (BALLOU, 2006), o que dificulta 0 gerenciamento dos itens em estoque (GAVIOLLI; BARBIERI, 2007) e acarreta elevados custos para as organizações (BOWERSOX; CROSS, 2001). 


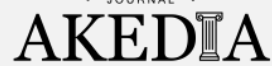

Os custos associados aos estoques são divididos em três categorias, segundo Ballou (1993) e Bowersox e Cross (2001), e devem ser cuidadosamente analisados antes de definirem-se a política de estoque que a empresa pretende adotar (GARDNER, 1980).

O primeiro tipo de despesas refere-se ao custo de manutenção de estoque. Essas despesas estão relacionadas ao armazenamento de produtos em estoque por um determinado período de tempo, e envolvem o custo de ocupação de espaço físico, como aluguel, manutenção predial, água, eletricidade, manuseio de equipamentos e mão de obra, custos de seguro. $O$ custo de capital fixo também se enquadra nesta categoria, que pode ser utilizado para outros investimentos, mas é fixo em estoque (LOVE, 1979).

Independentemente do tamanho da empresa, a importância do controle de estoque é óbvia para todas essas pessoas. Este é um setor que permite e exige a melhoria contínua da Logística e redução de custos, caso contrário, causará prejuízos e prejudicará gravemente a saúde do empreendimento. Um bom controle pode mostrar claramente os produtos mais vendidos e seu giro, de forma a entender o giro do seu estoque e evitar perdas desnecessárias.

De acordo com o que se mostra nas Figuras 1 e 2, os estoques podem ter de baixas a altíssimas quantidades de produtos, isso dependerá muito do tamanho e da demanda da empresa que o controla.

Figura 1 - Estoque de uma empresa de grande porte

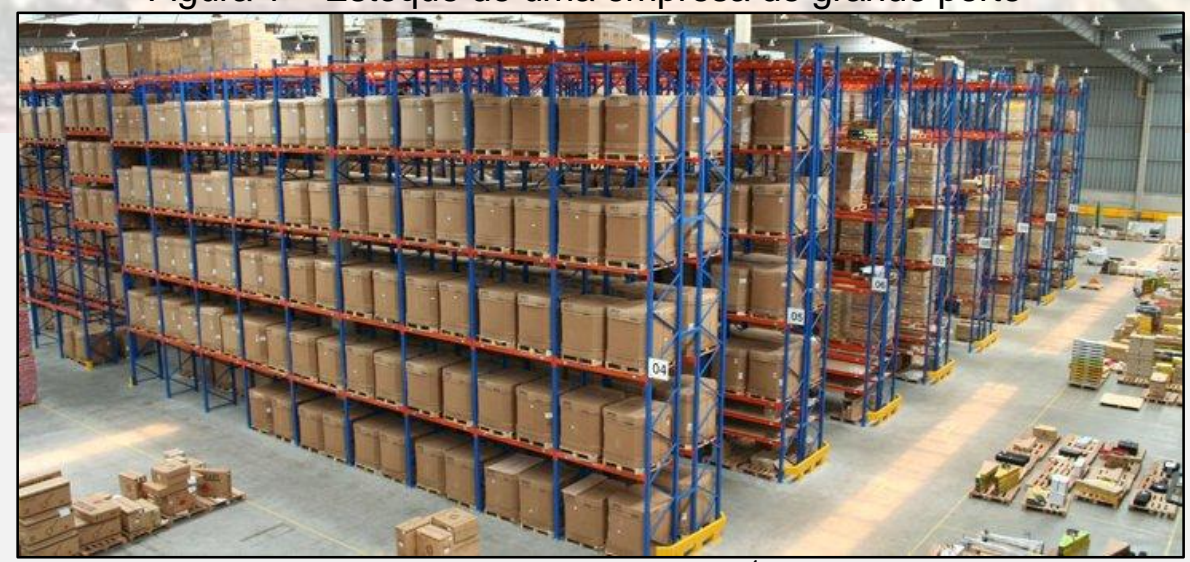

Fonte: Novida (2020) ${ }^{4}$.

\footnotetext{
${ }^{4}$ Disponível em: https://www.novida.com.br/blog/gestao-de-estoque/.
} 


\section{AKED}

Conclui-se, então, que o estoque é como a despensa de nossa casa. Sabemos quanto precisamos manter para atender às nossas necessidades e as de outras pessoas, sabemos onde escolher fornecedores (o mercado), sabemos quando investir e quando comprar mais "itens", dependendo das dificuldades atuais ou do negócio. Normalmente, praticaremos naturalmente alguns desses conceitos em nossas vidas e, às vezes, apenas uma pequena percepção será suficiente para entender que somos bons administradores, tal como se apresenta nas Figuras 1 e 2.

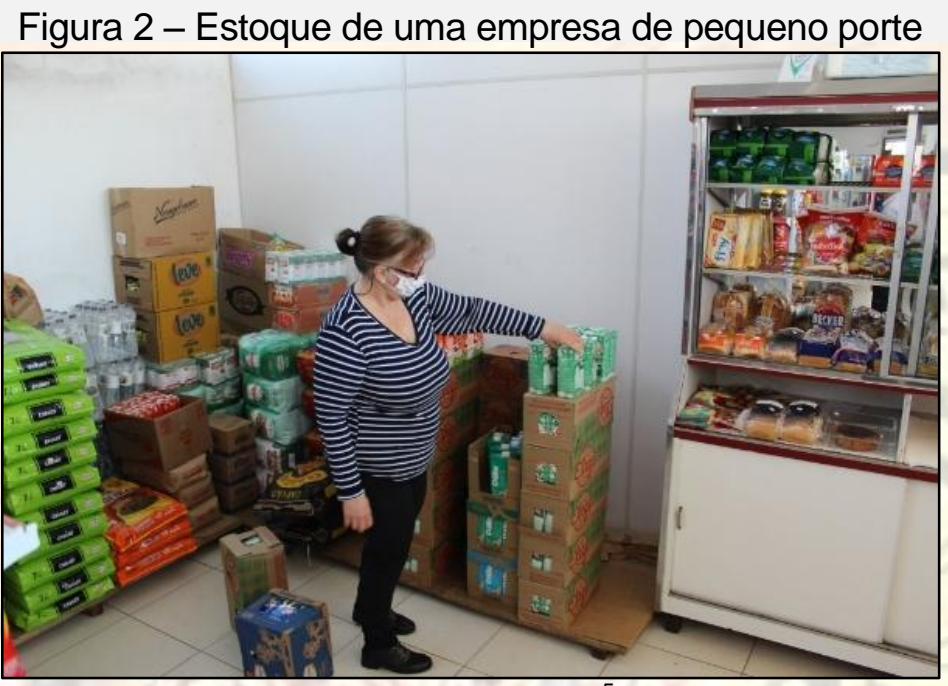

Fonte: Dally (2020)

O segundo tipo de custo envolvido no gerenciamento de estoque é o custo de reposição. Esta categoria inclui custos associados à geração de novos pedidos, os quais levam em consideração pedidos e emissões de transporte. De forma simplificada, podem-se determinar todos os custos como custos de reposição, que variam de acordo com a quantidade de pedidos feitos para a reposição de produtos em estoque (SILVER; PETERSON; PYKE, 1998).

O custo de escassez é o terceiro custo da gestão de estoques, o mais difícil de mensurar porque consiste no valor que a empresa não pode ganhar por não vender, ou seja, a contribuição unitária do produto. Os custos de escassez consistem também no custo incrível de não poder fornecer produtos aos clientes e, neste caso, as consequências para a empresa são diversas e difíceis de medir.

\footnotetext{
${ }^{5}$ Disponível em: https://www.jornalnh.com.br/noticias/regiao/2020/08/27/com-valor-mais-elevado-eestoques-mais-baixos--leite-e-o-novo-vilao-nas-compras.html
} 


\section{PREVISÃO DE DEMANDA E REGRESSÃO LINEAR}

As previsões de demanda possuem sua utilidade, tanto para a administração de processos quanto para a cadeia de suprimentos. Neste último caso, as previsões são importantes para coordenar ações com seus clientes e fornecedores. Quando se trata do processo, as previsões de produção são necessárias para projetar os diversos processos que envolvem toda a organização, inclusive identificar e resolver gargalos internos (KRAJEWSKI, MALHOTRA, RITZMAN, 2017).

Segundo Lelis (2016), o ato de prever a demanda por produto ou serviço constitui uma das questões mais difíceis de tratar no processo de tomada de decisão. Isto porque existe um intervalo de variação muito grande, o que nos leva a identificar padrões para antever o aumento ou a redução da demanda, nos diferentes períodos do ano.

Krajewski, Malhotra, Ritzman (2017) ressaltam que o processo de previsão de demanda permeia a organização como um todo, cruzando as áreas funcionais. Habitualmente, a previsão de demanda global tem início na área de marketing, contudo, clientes internos espalhados por toda a organização também dependem de previsões para formular e executar seus planos.

O departamento financeiro precisa das previsões para projetar seus fluxos de caixa e necessidades de capital. Os Recursos Humanos precisam delas para antever as necessidades de contratação e treinamento. O Marketing é uma fonte fundamental de informações de previsão de vendas, uma vez que está mais próximo dos clientes externos. Os gerentes de operações e logística precisam de previsões para que possam planejar níveis de produção, compras, oferta de serviços e aquisição de materiais, programações de força de trabalho e outputs, estoques e capacidades de longo prazo.

De forma geral, gerentes de todos os níveis necessitam de estimativas de previsão de demandas futuras, com o intuito de planejar atividades compatíveis com as prioridades competitivas de toda a empresa. 


\section{AKED』A}

Segundo Cunha e Coelho (2009), há muitas vezes, nas empresas, a necessidade de descrever e prever o comportamento de certas variáveis importantes para a tomada de decisões, tais como: custos, despesas, resultados.

As variáveis relevantes para os negócios podem ser previstas de diversas formas, como a utilização de um valor médio do que ocorreu no passado, uma pesquisa de mercado etc. Mas, à medida que o horizonte de planejamento se amplia, as previsões tornam-se mais difíceis de ser realizadas. E é possível resolver eficientemente tanto problemas de curto prazo como de longo prazo, por meio do estudo das relações entre as variáveis.

Entretanto, uma grande dificuldade enfrentada pelas pequenas empresas neste quesito da previsão de demanda aloca-se na escassez de recursos financeiros e tecnológicos, uma vez que a maioria dos softwares utilizados para gerar previsões de demanda é demasiadamente onerosa e os cálculos são também extensos e complexos.

Conforme apresentam Krajewski, Malhotra, Ritzman (2017), os métodos causais podem ser utilizados, quando há dados históricos disponíveis e quando se é possível identificar a relação entre os fatores a serem previstos e outros fatores externos ou internos, a exemplo de ações governamentais, anúncios publicitários etc. Essas relações são expressas em termos matemáticos e podem ser extremamente complexas. Pontos de inflexão na demanda e preparo de previsões de longo alcance podem ser previstos pela utilização de métodos causais, em que a regressão linear constitui um dos mais conhecidos e utilizados nesta área.

De acordo com Cunha e Coelho (2009), a regressão linear consiste em se determinar uma função matemática capaz de descrever o comportamento de determinada variável, denominada "dependente", com base nos valores de uma ou mais variáveis, denominadas "independentes". A regressão pode ser compreendida, portanto, como sendo o estabelecimento de uma relação funcional entre duas ou mais variáveis envolvidas para a descrição de um fenômeno. 


\section{AKEDIA}

Paralelamente, a correlação linear é outra técnica que visa medir a força ou o grau de relacionamento entre as variáveis, sendo muito útil quando associada à regressão linear.

Krajewski, Malhotra, Ritzman (2017) apresentam que nos modelos de regressão linear simples, a variável dependente pode ser determinada em função de apenas uma variável independente e, desta forma, a relação teórica é explicita em uma linha reta:

$$
Y=a+b X(1)
$$

Em que:

$$
\begin{aligned}
& Y=\text { variável dependente } \\
& X=\text { variável independente } \\
& a=\text { interseção da linha no eixo } Y \\
& b=\text { inclinação da linha }
\end{aligned}
$$

A análise de regressão linear tem como objetivo determinar os valores de $\mathrm{a}$ e $\mathrm{b}$ que minimizem a soma dos desvios quadráticos dos dados reais da linha representada graficamente. Para esse propósito, são utilizados programas de computador, que para qualquer conjunto de observações combinadas para $\mathrm{Y}$ e $\mathrm{X}$, o programa calcula os valores de a e b e fornece medidas da previsão com acuracidade (KRAJEWSKI, MALHOTRA, RITZMAN, 2017).

Uma alternativa viável para pequenas empresas é utilizar o Pacote Rcommander (Rcdmr) do Software $R$, que é disponibilizado sob os termos da General Public License da Free Software Foundation, na forma de código aberto.

Para exemplificar a utilização do Software $R$ na realização de uma análise de regressão linear, nos nortearemos pelos dados apresentados por Krajewski, Malhotra, Ritzman (2017, p. 309), que exemplificam a experiência de um gerente de cadeia de suprimentos buscando uma maneira de melhor prever a demanda por dobradiças de porta, acreditando que a demanda está relacionada aos gastos com publicidade (Tabela 1). 


\section{AKED』A}

Tabela 1 - Vendas de Dobradiças e Publicidade por mês

\begin{tabular}{ccc}
\hline Mês & $\begin{array}{c}\text { Vendas } \\
\text { (em milhares de unidades) }\end{array}$ & $\begin{array}{c}\text { Publicidade } \\
\text { (milhares de US } \$ \text { ) }\end{array}$ \\
\hline 1 & 264 & 2,5 \\
\hline 2 & 116 & 1,3 \\
\hline 3 & 165 & 1,4 \\
\hline 4 & 101 & 1,0 \\
\hline 5 & 209 & 2,0 \\
\hline
\end{tabular}

Fonte: Krajewski, Malhotra, Ritzman (2017)

Sabe-se que a empresa gastará US\$1.750 em publicidade do produto. A ideia é utilizar a regressão linear para desenvolver a equação que represente a relação entre vendas e gasto com publicidade, o coeficiente de determinação e o erro padrão da estimativa, que são medidas importantes para a interpretação da análise de regressão.

Para tanto, utilizaremos o Software $R$ como mencionado anteriormente. Sua instalação é simples, bastando acessar o endereço https://www.r-project.org/ no navegador de internet e seguir as instruções para fazer o download. Ao abrir - Software $R$, a tela inicial apresenta um console (Figura 3) para que se utilizem os comandos por linha de código, o que torna seu uso mais complexo. Entretanto, existe a opção de se instalar o Pacote Rcommander (Rcdmr), e depois, é preciso carregar este pacote todas as vezes que utilizar o programa.

Figura 3 - Tela inicial do Software $R$

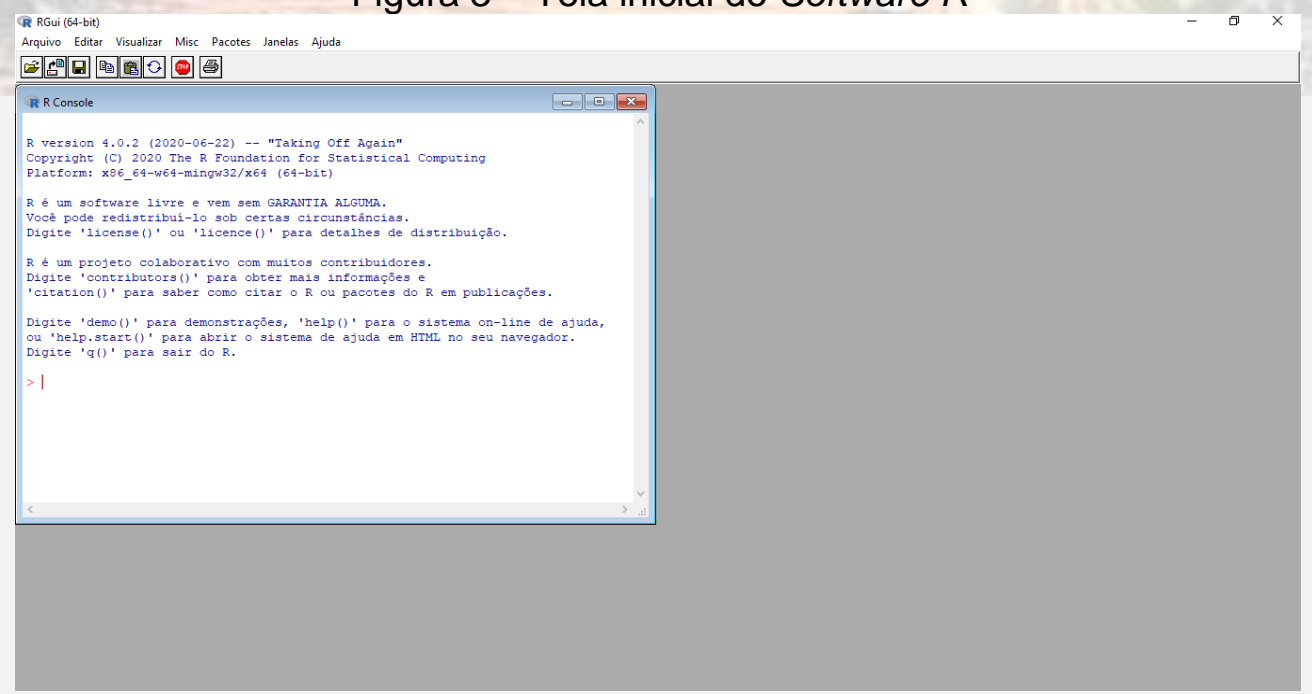

Fonte: Software $R$. 


\section{AKEDIA}

Para instalar o Pacote Rcommander (Rcdmr), basta selecionar "Instalar pacote(s)" no menu "Pacotes", e depois selecionar "Rcdmr" na lista de opções e seguir as recomendações. Após instalado, é preciso selecionar o Pacote Rcdmr na opção "Carregar pacotes" no menu "Pacotes" (Figura 4).

Figura 4 - Seleção do Pacote Rcdmr

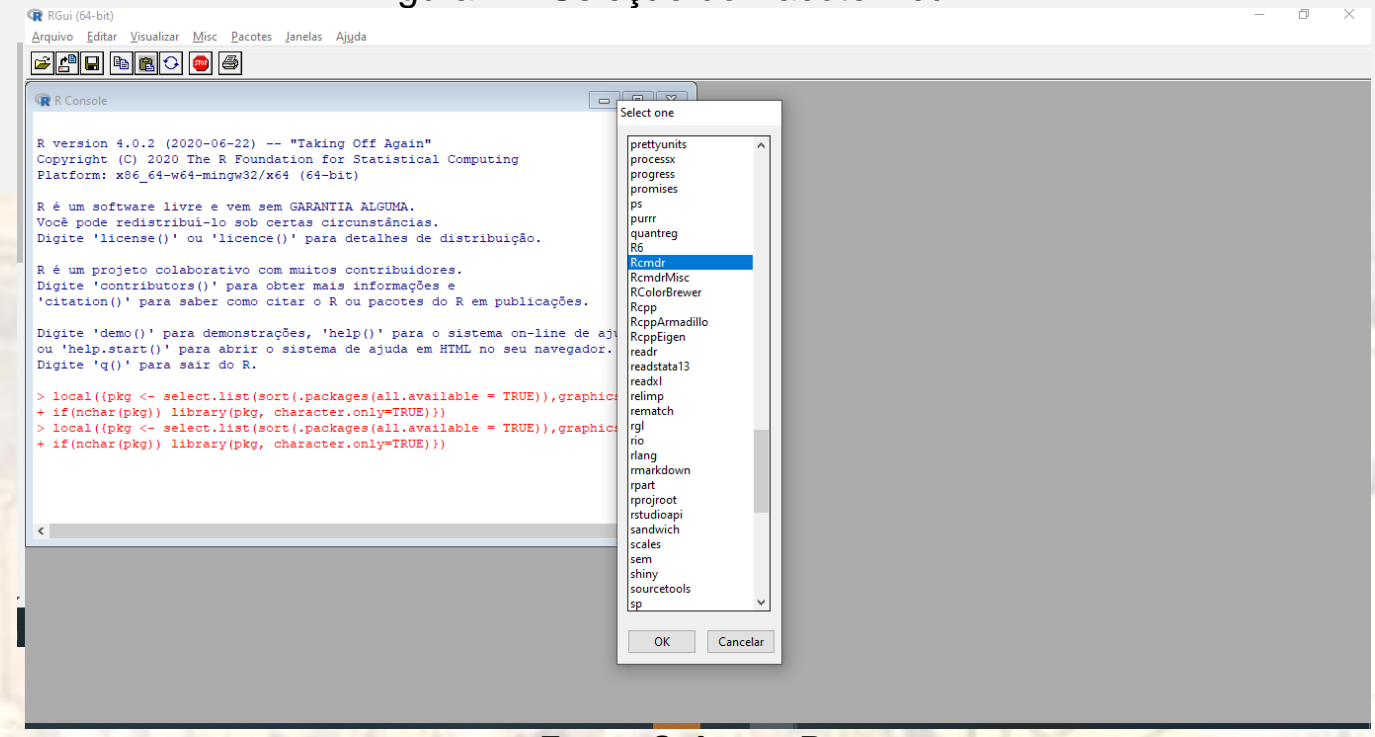

Fonte: Software $R$

A tela do Pacote Rcommander é mais intuitivo e fácil de utilizar. Os comandos estão organizados em menus, que apresentam diversas ferramentas estatísticas disponíveis para utilização (Figura 5).

Figura 5 - Tela do Pacote Rcommander

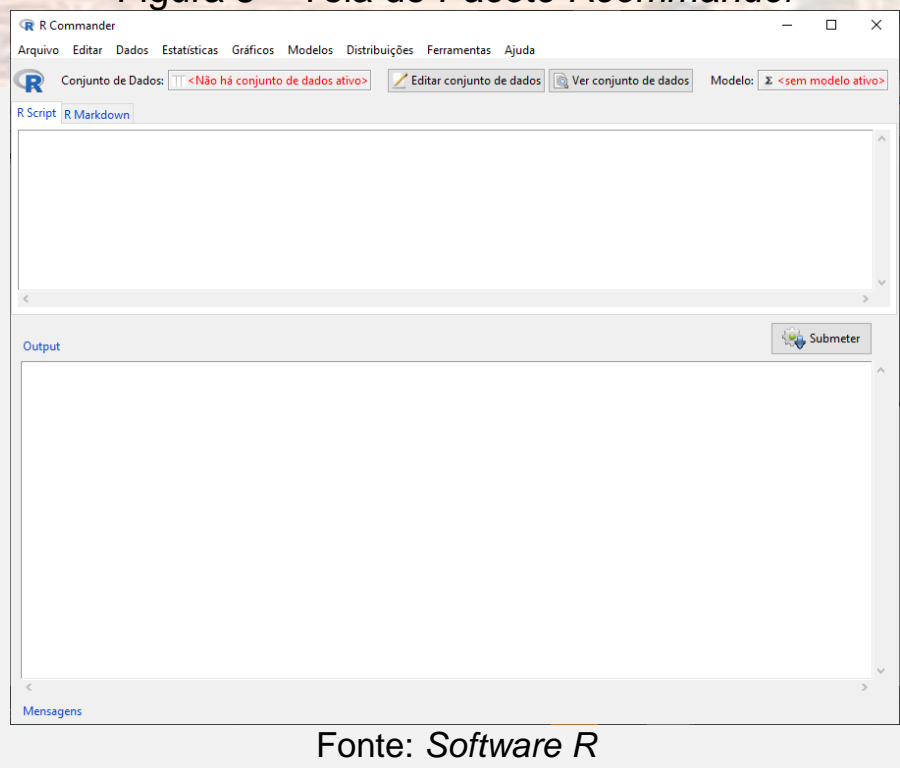




\section{AKEDIA}

No menu Dados, é possível criar um novo conjunto de dados, carregar um conjunto de dados existente ou importar arquivos com conjunto de dados oriundos de outros programas. No menu Estatísticas/Ajuste de modelos, é possível selecionar a "Regressão Linear", a definição do modelo de regressão, identificando qual é a variável dependente e qual é a variável independente e o software apresentará o resultado da análise, fornecendo os coeficientes da equação, bem como os valores do coeficiente de regressão linear.

Para os dados apresentados na Tabela 1, os resultados estão na Figura 6. Deste modo, temos que a equação resultante da análise de regressão linear é dada por:

$$
Y=-8,135+109,229 X(2)
$$

Como sequência dos resultados, temos também que o coeficiente de determinação da amostra $\left(r^{2}=0,9595\right)$ mede quanta variação na variável dependente em torno de sua média é explicada pela linha de regressão. 0 coeficiente de correlação $(r=0,9795)$ é a raiz quadrada do coeficiente de determinação, e mede a direção e a intensidade da relação entre a variável independente e a variável dependente. Esse valor pode variar de $-1,00 \mathrm{a}+1,00$, sendo que nos extremos, essa relação é muito forte e próximo de zero, essa relação não existe. Assim, como o coeficiente de correlação é muito próximo de $+1,00$, entende-se que existe uma relação positiva forte entre vendas e gastos com publicidade. O coeficiente de determinação implica que $95,95 \%$ da variação de vendas se devem aos gastos com publicidade.

Figura 6 - Resultado da análise de regressão linear para os dados da Tabela 1
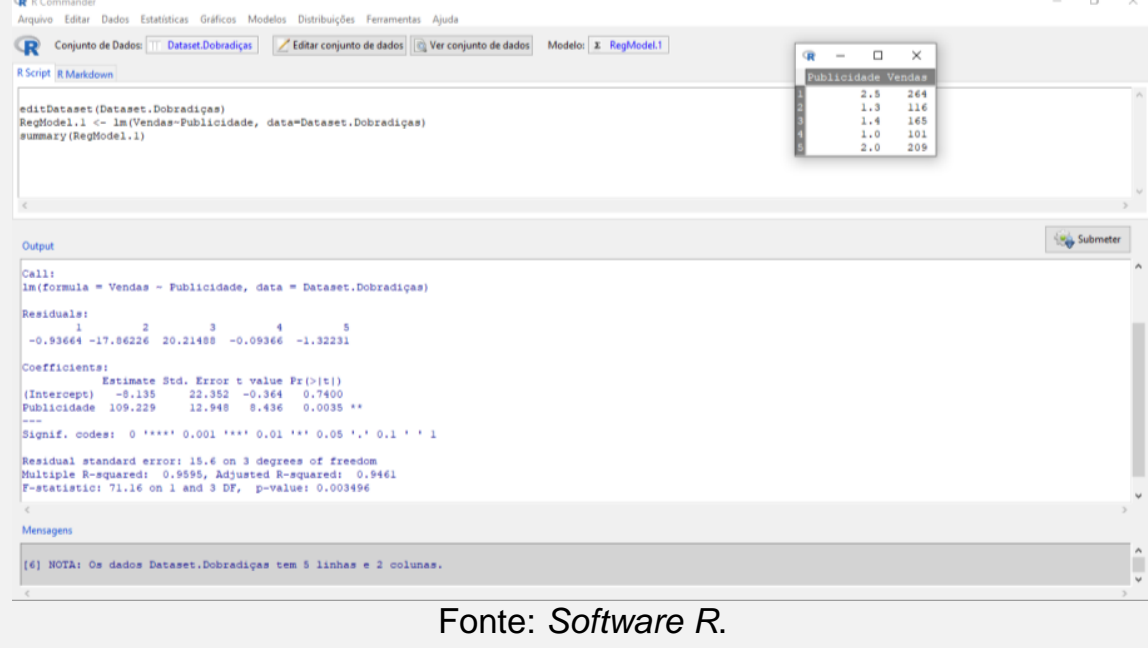


\section{AKED』A}

Terminando o exemplo aqui explorado, vemos que o gerente da cadeia de suprimentos tem agora a equação definida pelo modelo de regressão linear para o planejamento dos níveis de produção para o próximo período, baseado na informação de que o gasto com publicidade será de US\$1.750.

Assim, substituindo o valor de $\boldsymbol{X}$, temos que a previsão para o mês 06 é $\mathrm{Y}=-8,135+109,229(1,75)=183,016$ ou 183.060 unidades.

De acordo com Krajewski, Malhotra, Ritzman (2017), é possível observar que muitas variáveis independentes possam afetar a variável dependente. Assim, a análise de regressão múltipla pode ser utilizada para determinar uma equação de previsão para a variável dependente em função de diversas variáveis independentes. E, para encontrar um modelo nestas condições, o Software R, por meio do Pacote Rcommander, também pode ser utilizado sem maiores complicações.

\section{CONSIDERAÇÕES FINAIS}

Para formar cidadãos participativos, é preciso levar em consideração a noção de conhecimento geral dos fatos sociais e não somente de alfabetização ou domínio da escrita. A formação do profissional que trabalhará nas empresas do futuro deve ser centrada numa perspectiva política, social e cultural, possibilitando uma leitura estatística do mundo, que compreende a leitura e a escrita de dados como produtos de uma prática social em processo, na qual o sujeito e a educação precedem a escolarização.

A sociedade evolui de tal forma que os fatos se sucedem diariamente, necessitando de atenção especial em todos os ramos. A atividade empresarial se depara com novas formas de relacionamentos, seja na gestão de seus Recursos Humanos, na própria situação concorrencial, nas mutações corporativas etc. Por isso, é possível afirmar que as inserções de determinados mecanismos no cotidiano das pessoas refletem diretamente na gestão empresarial, que deve estar preparada para digerir as transformações.

Uma companhia depende, certamente, de ferramentas e softwares para o controle e organização de seus estoques, visando à necessidade de não se 
perderem, evitando a necessidade de recontagens por perdas em seus estoques. Essas ferramentas ou softwares utilizam-se da Estatística, a fim de obter resultados plausíveis para o que se está pedindo e, de tal modo, que se obtenha o que se espera dos serviços que estão proporcionando.

De certo modo, percebe-se que a Estatística está presente não só em empresas, mas, sobretudo, em todo o cotidiano dos indivíduos, nas circunstâncias em que os mesmos usam técnicas de cálculos para solucionar problemas ou até mesmo realizar uma conta básica de Probabilidade ou definir porcentagens para um acréscimo ou desconto.

Nos números, as chances estão diariamente fazendo parte das vidas das pessoas. Por este motivo, a ferramenta Estatística seria, de longe, uma das escolhas para o controle ou organização de estoques de empresas, fazendo com que o gerente que nela se aprofunde cresça profissionalmente.

Nesta pesquisa, discutiu-se sobre conceitos de Estatística e administração de estoques, com foco sobre as previsões de demanda e, mais especificamente em métodos causais, com o auxílio do Software $R$, uma ferramenta computacional viável para utilização em pequenas empresas.

Desta forma, atendemos ao o objetivo desta pesquisa, que foi o de identificar uma alternativa viável e compatível a pequenas empresas para realizar previsão de demanda, constituindo-se de uma ferramenta importante para tomada de decisão em administração de estoques, utilizando ferramentas estatísticas complexas e recursos computacionais eficientes.

A esperança de qualquer empresa é prever o que os clientes desejam e o quanto querem prevenir ou mesmo evitar a incerteza na demanda. Alguns deles são baseados no número de pedidos, no número de vendas em anos anteriores, no número de entregas executadas no prazo, enfim, todas as situações possíveis para atender a demanda com prazos e quantidades exatas. Porém, para uma empresa poder produzir, é sempre difícil atender à demanda sem erros, seja no processo em si ou com o fornecedor, o que causará problemas internos e a insatisfação do cliente. Quando se falar sobre ações, se estará falando sobre valor e balanceamento do estoque, o que, em síntese, requisitará aumento de custos. 


\section{REFERÊNCIAS}

ALVES, C. C. Gráficos de Controle CUSUM: um enfoque dinâmico para a análise estatística de processos. Florianópolis. Dissertação de Mestrado - Centro Tecnológico do Programa de Pós-Graduação em Engenharia de Produção. Universidade Federal de Santa Catarina, 2003.

ANDRADE, R. et al. Estatítica aplicada. Lisboa: Edições Sílaba, 1996.

BARBETTA, Pedro Alberto. Estatística aplicada às ciências sociais. $8^{\mathbf{a}}$ ed. Florianópolis, SC: UFSC, 2012.

BALLOU, R. H. Gerenciamento da cadeia de suprimentos: Logística Empresarial. 5 ed. Porto Alegre: Brookman, 2006.

BALLOU, R. H. Logística Empresarial. São Paulo: Atlas, 1993.

BOWERSOX, D. J.; CROSS, D. J. Logística Empresarial: o processo de integração da cadeia de suprimentos. São Paulo: Atlas, 2001.

BONAFINI, F.C. Estatística. São Paulo: Pearson Education do Brasil, 2012.

CORRÊA, C. A.; CORRÊA, H. Administração de Produção e Operações: manifatura e serviços - uma abordagem estratégica. São Paulo: Atlas, 2006.

FABER, B.; LARSON, R. Estatística aplicada. São Paulo: Prentice Hall, 2004.

GAVIOLLI, L. S.; BARBIERI, J. C. Política de vendas e estoques, baseada em sistemas de classificação de produtos: desenvolvimento teórico e sua aplicação em empresa do setor eletro-eletrônico. Gestão \& Regionalidade, v. 23, n. 66, 2007.

GARDNER, E. S. Inventory theory and gods of Olympus. Interfaces, v. 10, n. 4, 1980.

KRAJEWSKI, L. J.; MALHOTRA, M. K.; RITZMAN, L. P. Administração de produção e operações. (tradução de Sônia Midori Yamamoto). 11. ed. São Paulo: Pearson Education, 2017.

LEANDRO, F. L. A utilização da estatística como ferramenta na tomada de decisão: estudo de caso em uma indústria de base. Monografia de Conclusão de Curso de Engenharia. Minas Gerais: Universidade Federal de Juiz de Fora, 2008.

LEVIN, J.; FOX, J.A. Estatística para ciências humanas. São Paulo: Prentice Hall, 2004.

LÉLIS, E. C. Administração de materiais. São Paulo: Pearson Education do Brasil, 2016.

LOVE, S. Inventory Control. New York: McGraw-Hill, 1979.

MARSHALL JÚNIOR, I; CICERRO, A. A.; ROCHA, A. V.; MOTA E. B.; LEUSIN, S. Gestão da Qualidade. Rio de Janeiro: FGV, 2006. 
MCCLAVE, J.; BENSON, P. G.; SINCICH, T. Estatística para administração e economia. São Paulo: Pearson Prentice Hall, 2009.

MORETTI, L. G. Estatística Básica: probabilidade e inferência. São Paulo: Pearson Prentice Hall, 2010.

NEUFELD, J.L. Estatística aplicada à Administração usando Excel. São Paulo: Prentice Hall, 2003.

PRODANOV, C. C.; FREITAS, E. C. Metodologia do trabalho científico: métodos e técnicas de pesquisa e do trabalho acadêmico. 2. ed. Novo Hamburgo: FEEVALE, 2013.

ROSSETTI JÚNIOR, H. Educação Estatística no Ensino Básico: uma exigência do mundo do trabalho. Revista Capixaba de Ciência e Tecnologia. Vitória, n. 2, p. 35-37, 1. Sem. 2007.

SLACK, N.; CHAMBERS, S; JOHNSTON, R. Administração da Produção. 2 ed. São Paulo: Atlas, 2002.

SILVA, E. M.; SILVA, E. M.; GONÇALVES, V.; MUROLO, A. C. Estatística 1. 4⿳亠丷. . ed. São Paulo: Atlas, 2010.

SILVER, E. A.; PETERSON, R.; PYKE, D. F. Inventory Management and Production Planning and Scheduling. 3 ed. New York: John Wiley \& Sons, 1998.

ULRICH, D., YOUNGER, J., BROCKBANK, W., \& ULRICH, M. RH de Dentro para Fora: Seis Competências para o Futuro da Área de Recursos Humanos. Rio Grande do Sul: Bookman Editora, 2013.

WEBSTER, A. L. Estatística aplicada à Administração e Economia. São Paulo: McGraw-Hill, 2006.

WANKE, P. Gestão de estoques na cadeia de suprimentos: Decisões e modelos quantitativos. Rio de Janeiro: Atlas, 2003. 